\title{
AQUI VEREIS PRESENTE COISAS QUE JUNTAS SE ACHAM RARAMENTE
}

\author{
SOUZA, Roberto Acízelo de. \\ Historiografia da Literatura Brasileira: textos \\ fundadores (1825-1888). \\ Rio de Janeiro: Caetés, 2014.
}

Patricia Regina Cavalheiro Pereira

Universidade de São Paulo

Com o verso de Camões, "Aqui vereis presente coisas que juntas se acham raramente", ${ }^{1}$ escolhido como epígrafe de sua coletânea, o professor e pesquisador Roberto Acízelo Quelha de Souza define bem o que os leitores terão diante de si ao abrirem a Historiografia da Literatura Brasileira: textos fundadores (1825-1888).

Os escritos reunidos no transcorrer das mais de mil páginas dos livros - cartas, ensaios, discursos, introduções e notas - nos levam ao encontro do ideário que fundamenta a "formação da história literária como disciplina", ${ }^{2}$ constituído durante o período "que se estende de 1805 a 1888", datas em que foram publicados dois importantes volumes, História da poesia e da eloquência portuguesa, ${ }^{3}$ de Friedrich Bouterwek, e História da literatura brasileira, de Sílvio Romero.

Ainda no início do texto introdutório, o organizador conta aos leitores que, com a apresentação de sua antologia, ele trazia "a pretensão de ocupar o espaço que estava reservado na bibliografia dos estudos literários brasileiros"4 a dois volumes de Guilhermino César (1908-1993).

Sabe-se que, depois de ter publicado Historiadores e Críticos do Romantismo; 1 - a contribuição europeia: crítica e história literária, ${ }^{5} \mathrm{em}$ 1978, o autor mineiro tinha como objetivo levar a lume mais dois livros que privilegiariam a produção crítico-literária brasileira e teriam, portanto, o subtítulo "a contribuição nacional". Todavia, por razões desconhecidas, o propósito de Guilhermino César não foi levado adiante; logo, não se sabe como seria a continuação de sua obra. 
O que podemos assegurar é que o organizador da Historiografia da Literatura Brasileira foi bem sucedido ao aceitar o desafio de trabalhar com a ampla diversidade de textos com que lidou a fim de reconstituir uma unidade textual que apresentasse amplamente, por um viés oitocentista, o quadro de ideias que permeiam a história da literatura do Brasil, preenchendo, assim, a lacuna que existia na bibliografia histórico-literária a que se referiu.

Para tanto, foi preciso enfrentar a tarefa - desempenhada durante pelo menos quatorze anos, segundo nos relata o professor - de coligir, analisar, anotar e revisar tais textos. Empreitada que, certamente, não foi das mais leves, tendo em vista os percalços geralmente enfrentados por pesquisadores da área dos estudos literário-historiográficos.

É, pois, com o intuito de não deixar de lado o merecido reconhecimento a esse árduo trabalho, que seguiremos nas próximas linhas tratando dos recortes estabelecidos e dos critérios de organização adotados pelo pesquisador - apresentados ao leitor na introdução do primeiro volume -, antes de discorrermos sobre os textos de um dos mais significativos representantes das letras brasileiras, privilegiado na antologia.

\section{Com a palavra, o século XIX: a constituição de uma literatura}

Roberto Acízelo teve em mãos uma ampla variedade de escritos ao organizar a sua Historiografia da Literatura Brasileira. Pensando em "reunir a parte nacional do conjunto de textos inaugurais da historiografia literária do Brasil", ${ }^{6}$ o primeiro ponto levantado por ele foi a nacionalidade dos autores - brasileiros, com exceção de três: o chileno Santiago Nunes Ribeiro, o francês Carlos Emílio Adet e o espanhol Antônio Deodoro de Pascal. Todos, contudo, radicados no Brasil.

O período de publicação dos textos, como mencionado anteriormente, também foi uma de suas preocupações; para Acízelo, o recorte temporal deveria ser restrito ao da pós-independência, que visava a implantação de "uma literatura original nos trópicos". ${ }^{7}$ A terceira baliza que o organizador esclareceu, por fim, foi a publicação do que chamou de "estudos de intenções generalistas", que não tinham como alvo um escritor específico, dando, assim, "ensejo a considerações de ordem mais ampla, relativas ao conceito de literatura brasileira e sua história". 8

Definidos os preceitos gerais, são apresentados os seis "subconjuntos" textuais que o leitor encontrará na antologia. No primeiro, compos- 
to por "introduções e antologias de poesia, de conteúdo historiográfico menos ou mais desenvolvido", ${ }^{9}$ estão as reflexões de Januário da Cunha Barbosa, em "Por um Parnaso brasileiro" (1829-1832), e de Joaquim Norberto de Souza Silva, em "Introdução histórica sobre a literatura brasileira" (1859-1860), para citar apenas dois nomes.

No segundo, formado por "ensaios que contêm verdadeiras declarações de princípios para a instituição de uma literatura brasileira autêntica e emancipada", ${ }^{10}$ encontramos, a título de exemplo, o "Discurso sobre a história da literatura brasileira do Brasil" (1836), de Gonçalves de Magalhães, e "Para a regeneração intelectual do Brasil" (1843), de José Inácio de Abreu e Lima.

No subconjunto seguinte, composto por ensaios que são "sínteses históricas da literatura brasileira", ${ }^{11}$ assinalo dois escritos: "Do atraso intelectual do Brasil" (1835), de José Inácio de Abreu e Lima, e “A literatura brasileira contemporânea" (1874), de Antônio Henriques Leal. Na sequência, estão os "textos introdutórios a histórias da literatura", ${ }^{12}$ dos quais destaco "Noção e divisão de literatura" (1862) de Fernandes Pinheiro.

Há, ainda, a reunião de "ensaios dedicados a análises de obras específicas"13 no quinto subconjunto - cujo escrito de destaque é o "Ensaio crítico sobre a coleção de poesias do Sr. D. J. G. de Magalhães" (1833), de Justiniano José da Rocha - e os "textos destinados à autoconsiderações", ${ }_{14}$ no sexto e último, do qual sobressai a "Carta-prefácio a O cabeleira" (1876), de Franklin Távora. Antes de concluir, noto que, de todos os autores, o organizador trouxe dois textos ao leitor. Logo, estão em evidência os nomes de João Manuel Pereira da Silva, ${ }^{15}$ João Salomé Queiroga ${ }^{16}$ e José Martiniano de Alencar, por terem sido selecionados mais de três de seus escritos. ${ }^{17}$

Como pudemos observar, nas 1067 páginas da Historiografia da Literatura Brasileira é oferecida aos leitores do século XXI uma fonte abrangente e imprescindível de textos oitocentistas, corroborando a relevância da contribuição dos escritos e das ideias provenientes do século XIX para a constituição da nossa literatura. Ao final de sua introdução, no primeiro volume, o professor Roberto traz nomes que contaram a "história literária nacional"18 nos anos de 1900, como os de José Veríssimo (1916), Ronald de Carvalho (1919), Arthur Mota (1930), Nélson Werneck Sodré (1938) e Soares Amora (1955), e ressalta dois projetos de destaque, encabeçados por Afrânio Coutinho e Antonio Candido: A literatura no Brasil (1955-59) e Formação da literatura brasileira: momentos decisivos (1959), respectivamente. 
Com inegável pessimismo, depois de mencionar malfadadas publicações do século XXI, "mais ou menos alheias à reflexão em profundidade sobre os fundamentos teóricos e metodológicos"19 da historiografia literária brasileira, Acízelo parece não vislumbrar um futuro muito promissor aos estudos da disciplina. De toda forma, continua mantendo a convicção de que "não é possível prescindir por completo de quadros históricos e sínteses panorâmicas para se estudar literatura." ${ }^{20}$ Essa assertiva enseja, assim, a permanência de seu trabalho e o fato de ele manter-se tão vivo e necessário, pois, "se, por ora, um retorno puro e simples à prática clássica da história literária não se revela visível ou recomendável, talvez mais do que nunca [ainda] precisamos conhecer seus pressupostos e bases conceituais e metodológicas". ${ }^{21}$

Outra importante contribuição do livro, como pretendia seu idealizador, foi a disponibilização, "de modo sistemático, [de] um amplo corpus em que se pode acompanhar a constituição da disciplina [historiografia literária] no Brasil, dos esboços iniciais do tempo da independência à consumação do processo na década da proclamação da república." ${ }^{22}$ A compilação e organização dos textos facilita extremamente o acesso do leitor-pesquisador; um dos méritos centrais da coletânea a meu ver.

Mais um ponto relevante da obra é o fato de não haver um direcionamento pontual, que impõe uma visão pré-determinada na exposição dos textos. Aqueles, portanto, que se dedicarem à leitura do primeiro ${ }^{23} \mathrm{e}$ segundo ${ }^{24}$ volumes da Historiografia da Literatura Brasileira certamente terão a sensação de que há espaço para uma reflexão larga, na qual lhes caberá, e somente a si, reconhecer e analisar as diferentes perspectivas que constituem o panorama literário brasileiro.

Ao concluir as observações referentes à estruturação da antologia, não posso me esquecer de duas menções. Ainda no primeiro tomo, foram apresentados os critérios de estabelecimento dos textos e, em ambos os volumes, precedendo cada texto, o organizador teve o cuidado de disponibilizar uma biografia concisa do autor - item de extrema importância, que permite aos leitores conhecerem um pouco mais dos ensaístas e localizarem-se melhor temporalmente.

Não sendo possível abarcar nesta breve resenha todos os textos apresentados na coletânea, comentarei a seguir apenas duas das instigantes composições crítico-literárias de um dos mais notáveis homens de letras do Brasil. 


\section{cartas alencarianas}

De todos os escritos selecionados, foi aos de José Martiniano de Alencar (1829-1877) que o organizador da coletânea dedicou mais de uma centena e meia de páginas - precisamente 163 . No primeiro tomo da Historiografia da Literatura Brasileira, encontram-se reproduzidos oito dos textos críticos saídos da pena do escritor cearense, ${ }^{25}$ reflexões literárias que figuram entre as mais significativas da nossa literatura e são uma amostra do fôlego e da tenacidade que o romancista empregou na instauração de seu grandioso projeto ficcional.

Os dois conjuntos epistolares que marcam o início e o término da carreira do romancista - Cartas sobre A Confederação dos Tamoios e $O$ nosso cancioneiro: cartas ao Sr. Joaquim Serra - estão entre os pontos altos da seleção. As polêmicas que emergem das missivas alencarianas acendem ainda mais a discussão sobre a constituição da genuína literatura nacional e acerca do "abrasileiramento" da língua portuguesa, temas recorrentes na pauta oitocentista e que seguiram para o debate modernista do século XX.

As ideias defendidas por esse literato apresentam, ainda que de maneira questionável, por vezes, um movimento de certa inovação e ruptura tendo em vista as concepções literárias dominantes entre seus contemporâneos. Suas motivações talvez não fossem as mais nobres - pois ele se armava das missivas, em geral, com a finalidade primeira de atacar ou simplesmente enfrentar os desafetos -, contudo, não podemos perder de vista que as controvérsias por ele criadas ou incitadas ensejam discussões que se prolongaram na história da literatura brasileira.

Gênero textual muito empregado na obra de José de Alencar, presente nos momentos de manifestação de suas posições - fossem elas políticas ou literárias -, a carta, pública em especial, é elemento marcante de sua trajetória. Encontrar esses ensaios epistolares na coletânea demonstra o quão representativo foi o papel desempenhado por eles, não apenas na senda alencariana, mas notadamente no percurso histórico das letras brasileiras.

Sem sombra de dúvida, duas das leituras altamente recomendadas do livro, que é indiscutivelmente, uma grande obra.

NOTAS

${ }^{1}$ Verso extraído de Os Lusíadas, canto X. 
${ }^{2}$ SouzA, Roberto Acízelo de. Historiografia da Literatura Brasileira: textos fundadores (1825-1888), p.15-16.

${ }^{3} \mathrm{O}$ organizador da coletânea nos lembra que a História da poesia e da eloquência portuguesa é o quarto volume da obra História da poesia e da eloquência desde o século XIII. A relevância dos livros citados está no fato de a publicação de Friedrich Bouterwek apresentar as primeiras considerações sobre dois escritores brasileiros - Antônio José da Silva e Cláudio Manuel da Costa - e o texto de Sílvio Romero ter consolidado a disciplina "pela abrangência e fundamentação conceitual" que apresentou.

${ }^{4}$ Ibidem, p.16.

${ }^{5}$ A referência completa é Historiadores e Críticos do Romantismo; 1 - a contribuição europeia: crítica e história literária. São Paulo: Edusp; Rio de Janeiro: Livros Técnicos e Científicos.

${ }^{6}$ SouzA, Roberto Acízelo de; opus citatum, p.17.

${ }^{7}$ Ibidem, p. 17.

${ }^{8}$ Ibidem, p.17.

${ }^{9}$ Ibidem, p. 18 .

${ }^{10}$ Ibidem, p. 18.

${ }^{11}$ Ibidem, p. 18.

${ }^{12}$ Ibidem, p. 18.

${ }^{13}$ Ibidem, p. 19.

${ }^{14}$ Ibidem, p. 19 .

${ }^{15}$ Os textos selecionados - "Estudos sobre literatura" (1836), "História literária do Brasil" (1843-1848) e "A história do Brasil e o desenvolvimento das letras" (1858) - estão no primeiro volume.

${ }^{16}$ No segundo volume, encontram-se os cinco textos do autor: "Prólogo [ao $\mathrm{Ca}$ nhenho de poesias brasileiras]" (1870), "Advertência [a Maricota e o padre Chico]" (1871), "Prólogo [a Arremedos]" (1873), "Carta a Stokler" (1873) e "Carta-resposta a Stokler" (1873).

${ }^{17}$ Uma observação que não deve ser esquecida: o texto "Periodização da literatura brasileira: plano para um curso (1867)", de Francisco Sotero dos Reis, parcialmente transcrito no primeiro volume da Historiografia da Literatura Brasileira, está integralmente disponível no Curso de Literatura Portuguesa e Brasileira: fundamentos teóricos e autores brasileiros - organizado, mais uma vez, por Acízelo -, onde constitui texto introdutório ao volume 3. A referência completa é: REIs, Francisco Sotero dos. Curso de literatura portuguesa e brasileira: fundamentos 
teóricos e autores brasileiros. SouzA, Roberto Acízelo de (Org.). Rio de Janeiro: Caetés, 2014.

${ }^{18}$ SouzA, Roberto Acízelo de; opus citatum, p.20.

${ }^{19}$ Ibidem, p.21.

${ }^{20}$ Ibidem, p.22.

${ }^{21}$ Ibidem, p.22.

${ }^{22}$ Ibidem, p. 22.

${ }^{23}$ No primeiro tomo, encontramos textos de José Bonifácio de Andrade e Silva, Januário da Cunha Barbosa, Justiniano José da Rocha, Gonçalves de Magalhães Francisco de Sales Torres Homem - Manuel de Araújo Porto-Alegre, José Inácio de Abreu e Lima, Gonçalves de Magalhães, João Manuel Pereira da Silva, Santiago Nunes Ribeiro, Antônio Francisco Dutra e Melo, Joaquim Norberto de Sousa Silva - Emílio Adet, Bernardo Joaquim da Silva Guimarães, Francisco de Paula Meneses, Francisco Adolfo de Varnhagen, Manuel Antônio Álvares de Azevedo, Manuel Antônio Duarte de Azevedo, José Martiniano de Alencar, na sequência em que foram dispostos pelo organizador da coletânea.

${ }^{24} \mathrm{O}$ segundo volume é composto por escritos dos seguintes autores, de acordo com a ordem estabelecida por Acízelo: Antônio Gonçalves Dias, Ferreira Dias, Manuel Odorico Mendes, Joaquim Maria Machado de Assis, Antônio Joaquim de Macedo Soares, José Vieira Couto de Magalhães, Joaquim Norberto de Sousa Silva, Francisco Inácio Marcondes Homem de Melo, Antônio Deodoro de Pascoal, Joaquim Caetano Fernandes Pinheiro, Benjamin Franklin Ramiz Galvão, Francisco Sotero dos Reis, Luís José Junqueira Freire, Tristão de Alencar Araripe Júnior, João Salomé Queiroga, Alexandre José de Melo Morais Filho, José Cristiano Stokler de Lima, Antônio Henriques Leal, João Capistrano de Abreu, João Franklin da Silveira Távora, José Antônio de Freitas, José Veríssimo Dias de Matos, Manuel da Costa Honorato, Sílvio Vasconcelos da Silveira Ramos Romero, Luís Gonzaga Duque-Estrada. ${ }^{25}$ Em ordem cronológica: "O estilo na literatura brasileira" (1850), as oito "Cartas sobre A confederação dos Tamoios" (1856), o "Pós-escrito [ao romance Diva]" (1865), "A língua portuguesa no Brasil: plano" (186?), "Literatura brasileira" (186?), "Bênção paterna" (1872), "O nosso cancioneiro: cartas ao Sr. Joaquim Serra" (1874) e "O teatro brasileiro: a propósito de O jesuita" (1875).

Recebido:26/10/2017

Aceito: 07/06/2018 